Article

\title{
Structure and Properties of Tantalum Coatings Obtained by Electron Beam Technology on Aluminum Substrates
}

\author{
Khatia Ananiashvili ${ }^{1}$, Mikheil Okrosashvili ${ }^{1}$, Tamar Loladze ${ }^{1}$, Natalia Valko ${ }^{2}$ and \\ Tomasz N. Koltunowicz ${ }^{3, * \text { (D) }}$ \\ 1 Department of Metallurgy, Materials Science and Metal Treatment, Faculty of Chemical Technology \\ and Metallurgy, Georgian Technical University, 69, M. Kostava Street, Tbilisi 0175, Georgia; \\ kh.ananiashvili@gtu.ge (K.A.); m.okrosashvili@gtu.ge (M.O.); t.loladze@gtu.ge (T.L.) \\ 2 Department of General Physics, Yanka Kupala State University of Grodno, 22, Ozheshko Street, \\ Grodno 230023, Belarus; N.Valko@grsu.by \\ 3 Department of Electrical Devices and High Voltage Technology, Lublin University of Technology, 38a, \\ Nadbystrzycka Street, Lublin 20-618, Poland \\ * Correspondence: t.koltunowicz@pollub.pl; Tel.: +48-81-538-4713
}

Received: 27 April 2020; Accepted: 26 May 2020; Published: 28 May 2020

\begin{abstract}
The paper deals with the study of the structure and properties of tantalum coatings formed by electron beam evaporation and deposition of tantalum powder on $300-450{ }^{\circ} \mathrm{C}$ aluminum substrate. The research results of surface morphology, phase and elemental composition show that high activity of an aluminum substrate and specific conditions for vapor-phase technology promote formation of tantalum coatings characterized by a high degree of crystalline grains, with high adhesion and hardness despite the surface cracks. It was observed that the optimum deposition temperature of tantalum on aluminum substrates varies from $300{ }^{\circ} \mathrm{C}$ to $350{ }^{\circ} \mathrm{C}$. These coatings demonstrate excellent physical and mechanical properties due to formation of intermetallic phases in the reactive zone.
\end{abstract}

Keywords: tantalum coatings; aluminum substrate; condensation temperature; structure; phase formation; reactive diffusion

\section{Introduction}

Currently technological advances, in particular, the development of rocket and space technology, nuclear energy, heat power engineering, microelectronics, aviation, mechanical engineering and medicine highlight the necessity for new materials and technologies or modification of known ones. The surface of parts in modern machines, airplanes or engines is under the heaviest load, since it is affected by the working environment and contacting machine parts at an early operation stage. Therefore, improvement of the product reliability and its surface parameters is a very acute issue. Applying special coatings on the surface of different products is one of the common processing methods, while the composition, structure and properties of the coatings may differ from the base metal.

Various coating methods are used in industry currently. Scientific and technical experience of dealing with concentrated flows has shown that the electron beam is the most effective source of energy for external material processing [1,2]. Moreover, it has the highest energy and absorption coefficient. Energy power and concentration in the beam vary from $1 \mathrm{MW}$ and higher, which is not the case with laser and plasma. Consequently, the material is heated at a very high speed before evaporation. High speed evaporation of most refractory elements and chemical compounds is available, and the condensate can be applied on any material, (even incompatible) with the best adhesion and controlled 
structure and properties. The coating thickness is easily controlled from the nanoscale and above (e.g., to millimeter range) [3,4].

In the modern world, the development of nuclear energy leads to the increase in radioactive waste. It is well-known that tantalum (Ta) has a high radiation resistance to neutrons and the gamma radiation. At the same time, it has a high melting point. The most common substrate for applying a tantalum coating is aluminum, as it is a lightweight metal with a low melting point. Such materials can be widely used in nuclear reactors, containers for storing and transporting radioactive waste and in space rocket technology.

Various factors influence physical and mechanical characteristics of tantalum coatings, the main of which are residual stresses significantly changing the surface morphology and adhesion to an aluminum substrate. The chief reasons for occurrence of the residual stresses are: the uneven temperature distribution in the substrate-coating system; a significant difference in thermal expansion coefficients and in the parameters of crystal lattices; phase and structural transformations in the substrate, coating, and the transition zone between them and the presence of various inclusions in the coating [5].

The paper [6] presents the deposition method of $\mathrm{Ni}, \mathrm{Nb}$ and Ta coatings with very good adhesion to an aluminum substrate at special temperature conditions. In order to form different temperature conditions for vapor phase condensation, a temperature gradient in the range of $100-600{ }^{\circ} \mathrm{C}$ has been created on the substrate. Research data were obtained after testing samples from different temperature zones. According to the results, the optimum range of tantalum condensation on aluminum substrate is $200-320^{\circ} \mathrm{C}$. The nature of the processes occurring at the substrate-Ta-coating interface is revealed at various stages of phase formation and is an integral part of the corresponding studies. Thus, the goal of the paper is to study the phase and elemental compositions, microhardness, and morphology of tantalum coatings on an aluminum gradient substrate obtained by electron beam technology at $300-450{ }^{\circ} \mathrm{C}$ condensation temperature.

\section{Experimental}

After electron beam evaporation of tantalum powder, it was deposited onto the aluminum $300-450{ }^{\circ} \mathrm{C}$ substrate. Tantalum powder (product No. 73MR-0001, lot No. IAM1283TAM, grain size $5 \mu \mathrm{m}$, "Inframat Advanced Materials," Manchester, ST, USA) was pressed to obtain $50 \times 30 \mathrm{~mm}$ cylindrical briquettes, and before evaporation it was melted in vacuum by electron beam. A flat aluminum (A6, 99.6\% Al, $120 \times 280 \times 2 \mathrm{~mm}$, “Auremo," Kiev, Ukraine) plate was used as a substrate, on which a temperature gradient was created in the range of $100-550{ }^{\circ} \mathrm{C}$ using a molybdenum furnace on one side and water cooling on the other.

The experimental part of the study was carried out on an electron-beam installation under high vacuum of (3.99-5.32) $\times 10^{-2}$ Pa resulting in coatings without undesired impurities.

The vacuum system consists of a BH-6 for a vacuum pump, ABП-8 and ZEISS vapor-oil diffusers and a BH-3 booster pump. $1.33 \times 10^{-2} \mathrm{~Pa}$ vacuum is achieved in the vacuum system within an hour. The system is controlled with an ionization-thermocouple vacuum gauge VIT-2 (ВИТ-2, "Mayak," Kursk, Russia).

The unit is equipped with two separate electron beam guns. Each gun has an autonomous power supply and control system, allowing the use of two different electron beams, each with controlled power and beam orientation. Automatic control systems provide continuous maintenance of the electron beam power throughout the cycle.

The design of the camera ensures independent pumping of air from technological and gun areas, resulting in a stable vacuum of $10^{-2} \mathrm{~Pa}$ in the range of the electron beam section, and smooth operation of electronic guns.

The original material is evaporated from a water-cooled copper crucible (Figure 1). The distance between the evaporator and the substrate is approximately $300 \mathrm{~mm}$. The focused electron beam can evaporate most of the refractory metals, alloys and chemical compounds with adjustable speed, completely eliminating the need of selection the source material based on its melting or evaporation 
temperature. It should be noted that water-cooled copper crucibles and vacuum processes ensure complete environmental safety and high purity of the steam flow and consequently, of the final product.

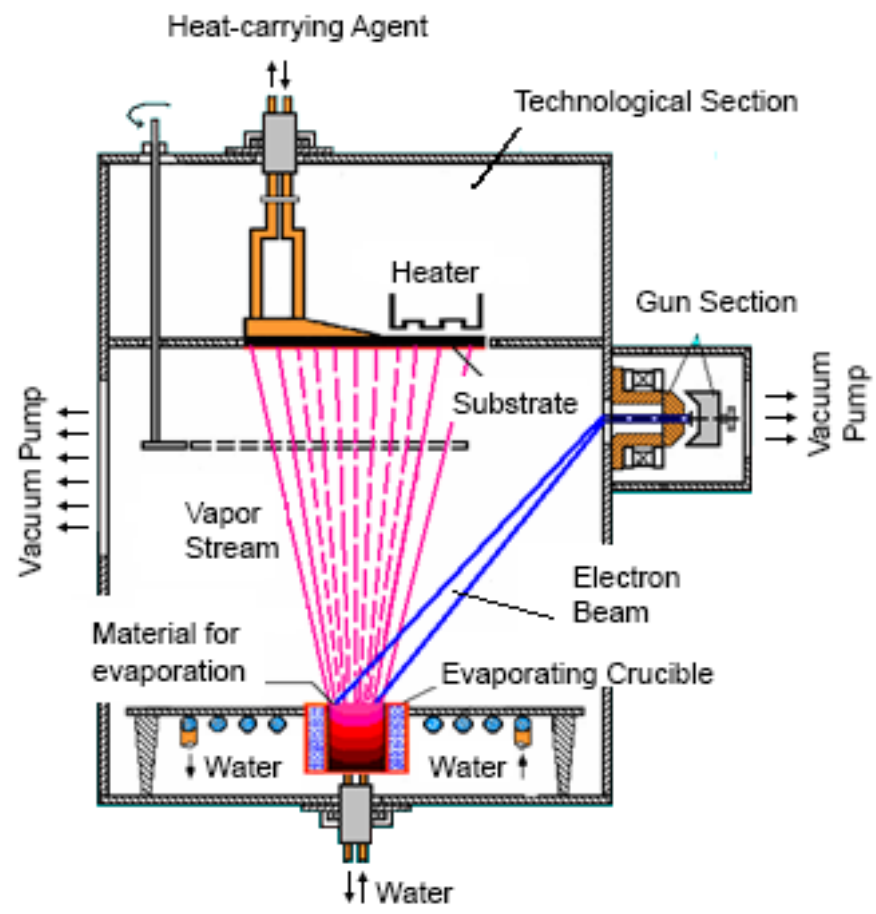

Figure 1. Scheme of the vacuum chamber of the electron beam installation.

Samples of tantalum coatings (coating thickness of $1 \mu \mathrm{m}$ ) on aluminum substrate were cut out of three temperature zones $\left(t_{\text {Cond }}=300-350{ }^{\circ} \mathrm{C}\right.$, $t_{\text {Cond }}=390-420{ }^{\circ} \mathrm{C}$, and $t_{\text {Cond }} \approx 450{ }^{\circ} \mathrm{C}$ ).

The surface morphology and elemental composition were studied on a JSM-5610 LV scanning electron microscope equipped with the EDX JED-2201 chemical analysis system (JEOL, Akishima, Japan). Accelerating voltage was $20 \mathrm{keV}$. The estimated depth range of electrons does not exceed $0.98 \mu \mathrm{m}$.

For determining the quantitative composition the characteristic X-ray fluorescence lines of $\mathrm{Al} \mathrm{K \alpha}$ and $\mathrm{Ta} \mathrm{M} \alpha$ with energies of $1.486 \mathrm{keV}$ and $1.709 \mathrm{keV}$ were used. It should be noted that the energy resolution of the detector is about $0.137 \mathrm{keV}$.

The phase composition was studied by X-ray diffraction (XRD) on a DRON-3M diffractometer (Bourevestnik, St. Petersburg, Russia) in the $\mathrm{Cu} \mathrm{K} \alpha$ radiation. Microhardness of the coating surface was measured on a CASON-59 HV microhardness tester (Jinan Kason Testing Equipment Co, Jinan City, Shandong Province, China).

The adhesion between Ta coatings and the aluminum substrate was investigated by the scratch method based on applying a scratches grid on the surface of testing coatings. The adhesion test was carried out in accordance with the interstate standard [6].

\section{Results and Discussion}

SEM images of surface morphology and cross-sections of the tantalum coatings deposited at the condensation temperature in the range of $300-450^{\circ} \mathrm{C}$ are presented in Figures 2-4. It is obvious that all research samples have thickness not exceeding $1 \mu \mathrm{m}$. Many surface cracks are observed.

Figure 2 shows that the coating, formed in the lowest temperature zone $\left(300-350^{\circ} \mathrm{C}\right)$, is characterized with initial crack formation. It is also confirmed by a cross-section image of the specimen showing a violation of the integrity of the condensed tantalum layer in relatively smaller areas. 

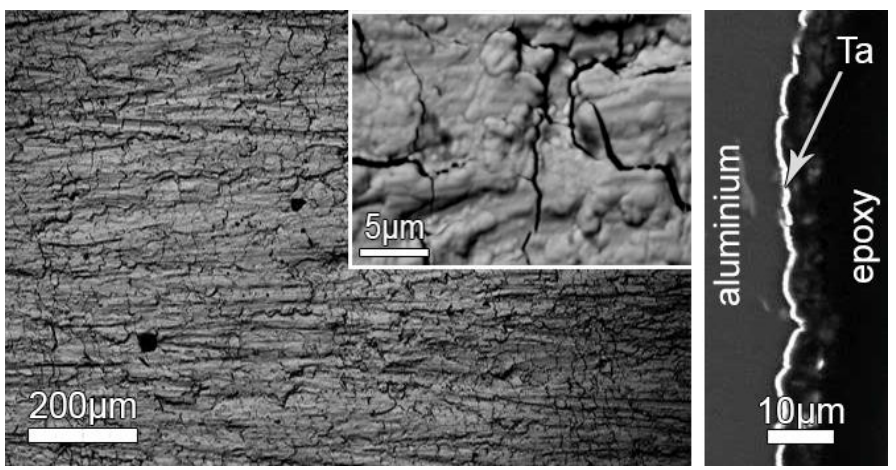

Figure 2. Surface microstructure $(200 \mu \mathrm{m})$ and $(5 \mu \mathrm{m})$ and view of tantalum coating on a gradient aluminum substrate $\left(t_{\text {Cond }}=300-350{ }^{\circ} \mathrm{C}\right)$.

As the condensation temperature rises up to $390{ }^{\circ} \mathrm{C}$ cracks open and the surface continuity is violated. Cross section images show that the discontinuity area of Ta coating is broadened (Figure 3).
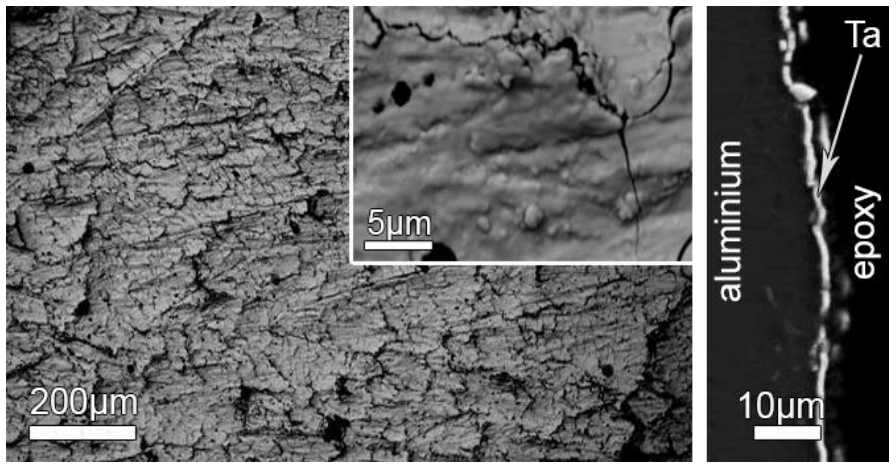

Figure 3. Surface microstructure $(200 \mu \mathrm{m})$ and $(5 \mu \mathrm{m})$ and cross-section view of tantalum coating on a gradient aluminum substrate $\left(t_{\text {Cond }}=390-420^{\circ} \mathrm{C}\right)$.

With subsequent increase in temperature to approximately $450{ }^{\circ} \mathrm{C}$ the surface is covered with tantalum spheres. Accordingly, the cross section shows broadening in the discontinuity area of $\mathrm{Ta}$ coating (Figure 4).
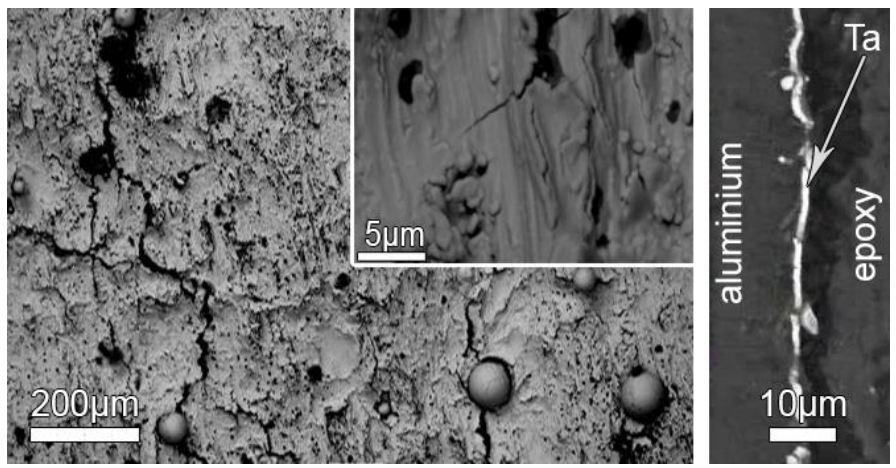

Figure 4. Surface microstructure $(200 \mu \mathrm{m})$ and $(5 \mu \mathrm{m})$ and cross-section view of tantalum coating on a gradient aluminum substrate $\left(t_{\text {Cond }} \sim 450{ }^{\circ} \mathrm{C}\right)$.

Atomic force microscopy (AFM) images of the Ta coatings on the aluminum substrate, formed from three temperature zones $\left(t_{\text {Cond }}=300-350{ }^{\circ} \mathrm{C}\right.$, $\left.t_{\text {Cond }}=390-420{ }^{\circ} \mathrm{C}, t_{\text {Cond }} \approx 450{ }^{\circ} \mathrm{C}\right)$, are shown in Figure 5. 
(a)

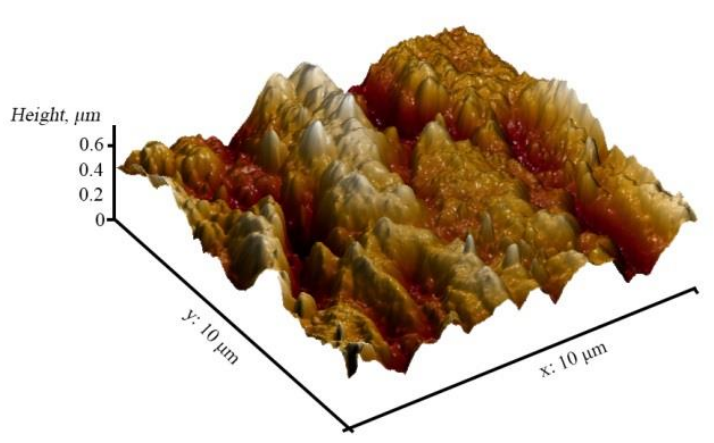

(b)

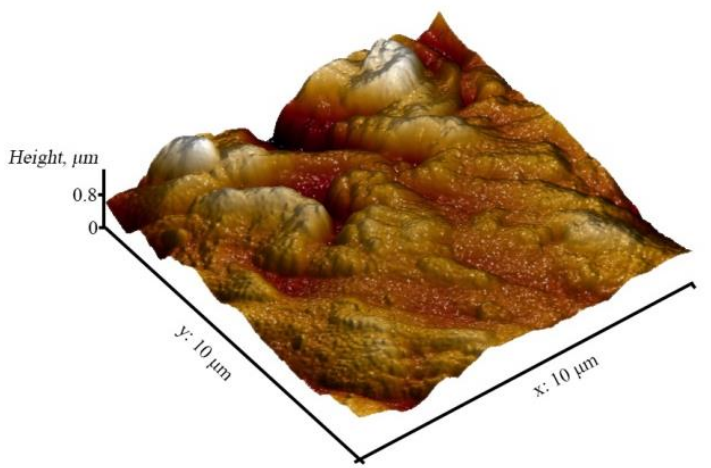

(c)

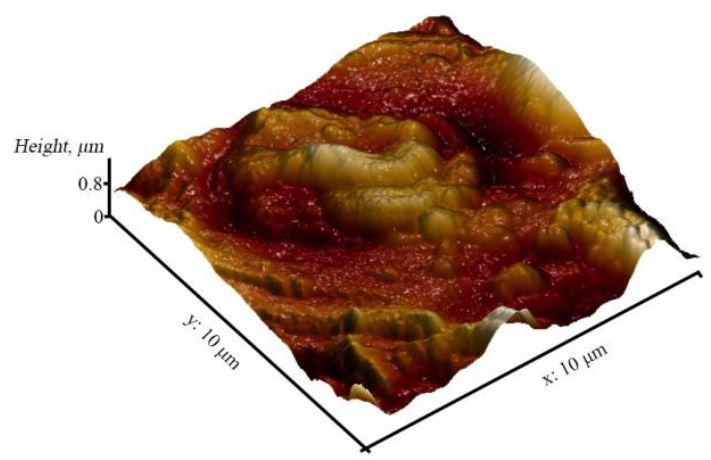

Figure 5. AFM images of the Ta coatings on the aluminum temperature gradient substrate. Condensation temperature: (a) $300-350{ }^{\circ} \mathrm{C}$, (b) $390-420^{\circ} \mathrm{C}$, and (c) approximately $450{ }^{\circ} \mathrm{C}$.

The investigation of the topography of Ta coatings using atomic force microscopy was provided on AFM-microscope Ntegra Spectra Solar (NT-MDT, Moscow, Russia) using a semi-contact regime. The AFM image revealed that grain size decreases gradually with the increase of condensation temperature.

It was revealed that the coatings of all investigated samples, taken from different temperature zones, despite the cracks, have excellent adhesion to the substrate ( 1 on a 4 scale, where 1 is the best rating). The results indicate that cracking of the Ta coating may be caused by the difference in the physical and mechanical properties between the condensed tantalum layer and the substrate, causing strains and residual stresses in the boundary zone between the coating and the substrate, ultimately resulting in decomposition of the condensed film integrity.

As for the residual stresses in Ta coatings, they can occur for various reasons; one of them is the difference between the thermal expansion coefficients of the substrate material and the coating. Thus, the thermal expansion coefficient values for Ta vary from $6.6 \times 10^{-6} \mathrm{C}^{-1}$ to $8.0 \times 10^{-6}{ }^{\circ} \mathrm{C}^{-1}$ in the temperature range of $20-500{ }^{\circ} \mathrm{C}$ and $20-1500^{\circ} \mathrm{C}$ respectively, while for $\mathrm{Al}$ it is equal to $25.6 \times 10^{-6} \mathrm{C}^{-1}$ in the temperature range of $20-300^{\circ} \mathrm{C}$.

The magnitude of thermal stresses also depends on the deposition temperature and rises steadily with the increase of condensation temperature. This is the reason for multiple surface cracks on the investigated Ta coatings when raising the condensation temperature.

In accordance with XRD analysis of the Ta coatings on an aluminum substrate, formed in the 300-350 ${ }^{\circ} \mathrm{C}$ temperature range, a multiphase system consisting of pure $\mathrm{Ta}$ (coating), $\mathrm{Al}$ (substrate) and intermetallic compound $\mathrm{Ta}_{2} \mathrm{Al}$ with tetragonal cells is revealed. Analysis of the diffraction patterns presented in Figure 6 shows that the increase of condensation temperature leads to the change in the structural phase of the Ta coatings. 


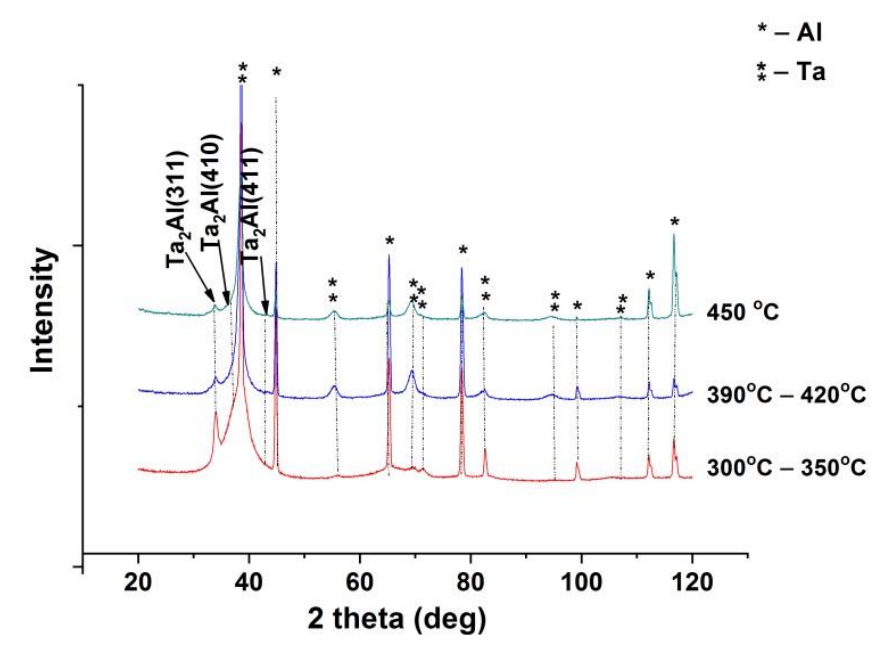

Figure 6. X-ray diffraction (XRD) patterns of a Ta coating on a gradient aluminum substrate. Condensation temperature: $300-350{ }^{\circ} \mathrm{C}$ (red), $390-420^{\circ} \mathrm{C}$ (blue), and approximately $450{ }^{\circ} \mathrm{C}$ (green).

Intensity redistribution of the diffraction peaks indicates changing in the mass fraction of phases. In particular, with the rise in condensation temperature, an increased intensity of peaks corresponding to $\mathrm{Al}$ is observed, which is associated with multiplying of surface cracks on the coatings. With rising of the condensation temperature, a decrease in the number of reflections, as well as their intensity corresponding to pure $\mathrm{Ta}$, is observed. The intensity of reflections from the $\mathrm{Ta}_{2} \mathrm{Al}$ intermetallic compound also decreases with increasing condensation temperature and practically disappears at $450{ }^{\circ} \mathrm{C}$ [7]. It should be noted that XRD data correlates with the data obtained during the study of the elemental composition. Figure 7 shows that $\mathrm{Al}$ content increases and Ta content decreases with rising of the condensation temperature of the tantalum on an aluminum substrate.

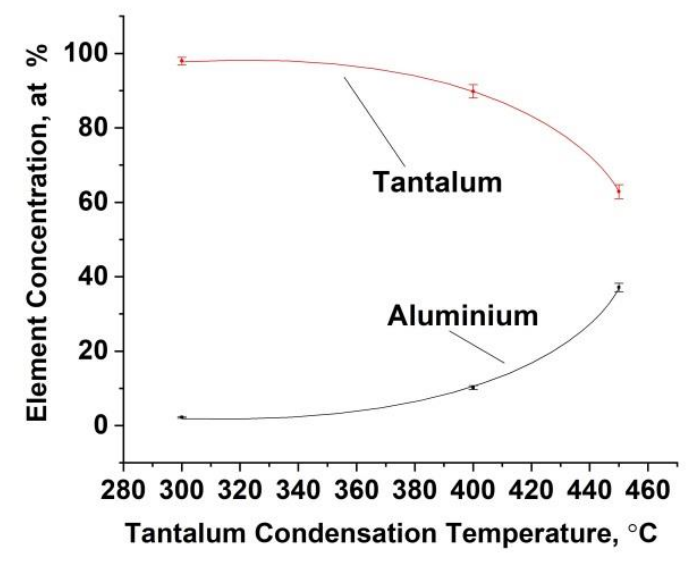

Figure 7. Dependence of the elemental composition (at \%) of Ta gradient coating on an aluminum substrate formed at different temperatures.

As indicated above, the relative increase of $\mathrm{Al}$ content is associated with crack formation and diffusion of $\mathrm{Al}$ from the substrate into the Ta-coating when raising the condensation temperature.

More detailed analysis of diffraction patterns shows that a full width at half maximum (FWHM) of main Ta diffraction maximums rise steadily with the increase in condensation temperature, pointing to the deposition of Ta coatings with a high degree of crystalline grain dispersion at high temperatures in the reactive-diffusion zone [7].

Such a complicated situation is expected during condensation of tantalum, a refractory element, - on an aluminum surface. According to the references and the results of personal studies [8], the formation of metastable or stable intermediate chemical compounds, characteristic for this system, cannot be 
ruled out upon reaching the appropriate concentration conditions of the components, notwithstanding low condensation temperatures.

It was found that with the simultaneous occurrence of solid-phase and reactive-diffusion processes, the formation of intermediate chemical compounds is possible by passing from one state to another through a metastable phase of a transitional composition [9-11]. Under conditions of great hypothermia and nonequilibrium crystallization, characteristic for vapor-phase technology, the formation of non-controlled, unpredictable metastable phases is possible. The situation at the substrate-coating interface is constantly changing in accordance with the change in technological parameters and the thickness of the condensed film. Therefore, the metastable compounds can be formed or disappear interacting with each other or with other reagents.

Based on the above mentioned, it must be assumed that the formation of a highly dispersed structure is a result of conversion of the $\mathrm{Ta}_{2} \mathrm{Al}$ to another chemical compound, being in an X-ray finely dispersed phase. This is also suggested by the fact that with the increase in condensation temperature the microhardness of the coating is continuously increased.

Figure 8 shows the dependence of microhardness of Ta coatings and of the physical broadening of the X-ray spectral line (110) (full width at half maximum FWHM) on condensation temperature in the diffraction patterns of Ta.

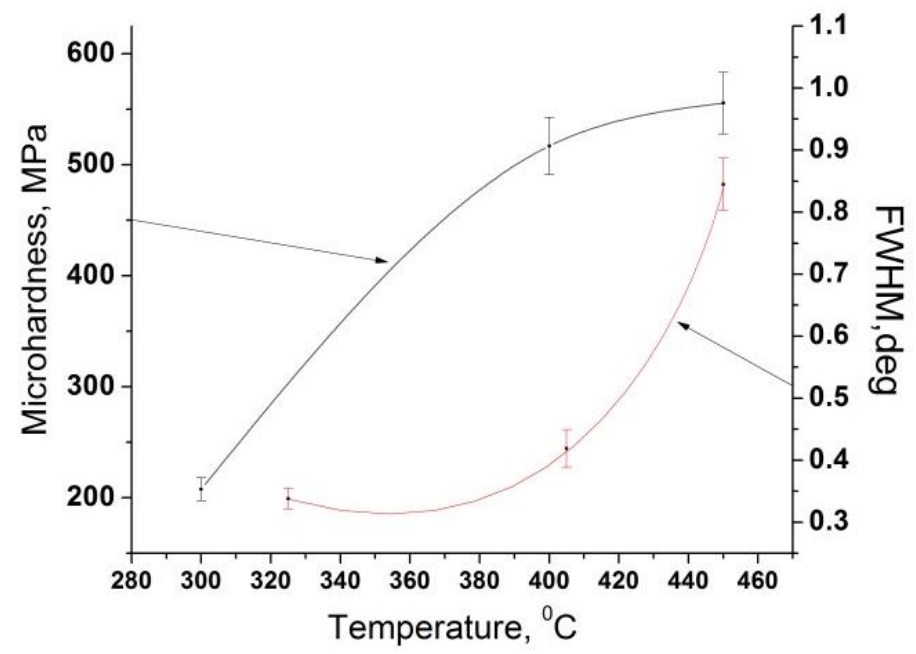

Figure 8. Dependence of microhardness (MPa) and broadening of X-ray spectral lines (110) on Ta condensation temperature.

It can be observed that the rise in Ta condensation temperature on an aluminum substrate leads to the steady increase in the width of the diffraction peaks, indicating an increment in the concentration of defects in Ta coatings and high degree of crystalline grain dispersion that indicates a possible microhardness of these coatings with the rise in condensation temperature.

\section{Conclusions}

Based on the research results of surface morphology, and phase and elemental composition, the main conclusion is that the phase formation process, the degree of adhesion to the substrate and obtaining a high-quality coating without any defects in the Al-Ta composite system are affected by the substrate temperature.

Above the upper limit of the optimal temperature range, the intermediate chemical compound $\mathrm{Ta}_{2} \mathrm{Al}$ is formed as a result of reactive diffusion. Upon cooling the sample this compound causes its cracking due to different physico-mechanical characteristics, narrowing the optimal condensation range within $200-350{ }^{\circ} \mathrm{C}$. 
Author Contributions: Conceptualization, K.A. and T.L.; methodology, M.O. and N.V.; validation, K.A., T.L. and N.V.; formal analysis, K.A., M.O, T.L., N.V. and T.N.K.; investigation, K.A., M.O and N.V.; data curation, K.A., N.V. and T.N.K.; writing-original draft preparation, K.A. and N.V.; writing—review and editing, T.N.K.; visualization, T.N.K.; supervision, K.A and N.V.; funding acquisition, K.A., M.O, T.L. and T.N.K. All authors have read and agreed to the published version of the manuscript.

Funding: This research was funded by Shota Rustaveli National Science Foundation of Georgia (SRNSFG) PHDF-18-736 "Development of the Technology for Obtaining Functional Coatings on the Special Substrate" and by the Polish Ministry of Science and Higher Education as a Science Fund of the Lublin University of Technology, at the Faculty of Electrical Engineering and Computer Science FN-28/E/EE/2019 “Researches of electrical, magnetic, thermal and mechanical properties of modern electrotechnical and electronic materials, including nanomaterials and diagnostic of electrical devices and their components".

Conflicts of Interest: The authors declare no conflict of interest. The funders had no role in the design of the study; in the collection, analyses, or interpretation of data; in the writing of the manuscript, or in the decision to publish the results.

\section{References}

1. Mattox, D.M. Handbook of Physical Vapor Deposition (PVD) Processing. Film Formation, Adhesion, Surface Preparation and Contamination Control. Society of Vacuum Coaters; Noyes Publications: Albuquerque, NM, USA, 1998.

2. Bunshah, R.F. Handbook of Deposition Technologies for Films and Coatings. Science, Technology and Applications; Noyes Publications: University of California at Los Angeles: Los Angeles, CA, USA, 1994.

3. Maslov, A.A.; Ostvald, R.V.; Shagalov, V.V.; Maslova, E.S.; Gorenyuk, Y.S. Chemical Technology of Niobium and Tantalum; Tomsk Polytechnic University: Tomsk, Russia, 2010. (In Russian)

4. Cristea, D.; Ghiuţă, I.; Munteanu, D. Tantalum Based Materials for Implants and Prostheses Applications. Bull. Transilv. Univ. Bras. Ser. I Eng. Sci. 2015, 8, 151-158.

5. Barvinok, V.A. Stressed State Control and Properties of Plasma-Sprayed Coatings; Mashinostroenie: Moscow, Russia, 1990. (In Russian)

6. GOST 9.302-88. Unified System of Protection against Corrosion and Aging. Metal and Non-Metal Coatings. Inorganic. Control Methods; Publishing House of Standards: Moscow, Russia, 1990.

7. Okrosashvili, M.N.; Razmadze, G.L.; Lomaia, T.P.; Loladze, T.O.; Peikrishvili, A.B. Technology of obtaining $\mathrm{Ni}, \mathrm{Nb}$ and Ta coatings on aluminum substrate. Trans. Georgian Tech. Univ. 2015, 3, 161-175. (In Russian)

8. Okrosashvili, M.; Kutelia, E.; Makharadze, T.; Topuria, M.; Peikrishvili, A. Phase Formation at the Condensation of a Vapor Stream and Associated Diffusion Reaction Surface Engineering. In Proceedings of the 5th International Surface Engineering Congress, Materials Park, OH, USA, 15-17 May 2006; pp. 102-105.

9. Okrosashvili, M.N.; Kutelia, E.R.; Miminoshvili, E.B.; Kakauridze, T.A. Impact of the substrate surface state on the structure and phase composition of oxide condensates. Probl. Spetsialnoi Elektrometallurgii 1999, 1, 26-31. (In Russian)

10. Kutelia, E.R.; Shalamberidze, O.P.; Golodze, N.A.; Maisuradze, N.I.; Dzigrashvili, T.A.; Tsivtsivadze, D.M.; Khakhanashvili, K.G. Electron Microscopy Investigation of the Crystallization Processes of Amorphous ZrO2 Films Prepared in Superhigh Vacuum. In Proceedings of the International Conference Zirconia'88-Advances in Zirconia Science and Technology, Bologna, Italy, 14-17 December 1988; Meriani, S., Palmonari, C., Eds.; Elsevier Science Publishers LTD.: New York, NY, USA, 1989; pp. 131-135.

11. Lashko, S.V.; Lashko, N.F. Soldering Metals; Mashinostroenie: Moscow, Russia, 1988. (In Russian) 